\title{
Replacement of Cement with Hypo Sludge Flyash and Sand with Quarry Sand
}

\author{
Manjunatha H, R. Malathi, J Mahipal, R. Saritha, T. Ashok
}

\begin{abstract}
This paper indicates the research on impact of modern waste materials to be particular lime slime, fly particles and quarry sand on compressive best, cut up elasticity and flexural characteristics of M30 grade concrete. Here in M30grade strong, concrete is in thing supplanted with the resource of lime slime 10 to 40 percentage and fly debris 10 to twenty percent, and sand is halfway supplanted through quarry dust (sand) 20 percentage in 5 aggregate extents. The consequences of these five blends are contrasted and managed combo. The blend quantity in with incomplete substitution of bond through way of lime ooze 10 percent, fly particles 10 percentage and with midway substitution of sand via using quarry dust 20 percentage, commonly yielded most fine outcomes over staying all blends.
\end{abstract}

Catchphrases: Lime Sludge, Quarry Sand, Fly Ash, cut up Tensile electricity, Compressive strength

\section{INTRODUCTION}

Concrete is an crucial material, this is to a brilliant volume being utilized in the development of structures, spans, asphalts, dams, marine and sterile systems. Because of the growing global ecological security mindfulness, and stricter pointers on overseeing modern-day squanders, the arena is gradually glancing in to searching into houses of mechanical squanders and coming across preparations on huge segment detail in order that may be implemented as auxiliary crude fabric for one-of-a-kind mechanical programs. Lime muck is a result of paper making in the paper production facility groups and fly particles is sideeffect of coal warmth energy flowers. Till this point in time, the ones effects implemented in other mechanical branches and within the subject of structural building developments, as an example, in concrete technology alongside clinker and in workmanship paintings for not unusual works. Thinking about the explicitness of physical and synthetic houses of fly particles and hypo-slime and the potential consequences for their usage in strong, this exploration artwork money owed the ability effects of utilizing fly particles and hypo-slop collectively as incomplete substitution of bond in concrete. The lower within the wellsprings of function sand and

Revised Manuscript Received on September 14, 2019.

Manjunatha H, Assistant Professor (SG),Department of Civil Engineering, Sri Ramakrishna Institute of Technology, Coimbatore. Tamil Nadu, India.

R. Malathi, Assistant Professor,Department of Civil Engineering, Siddhartha Institute of Technology and Sciences, Hyderabad, Telangana, India.

J Mahipal, Assistant Professor,Department of Civil Engineering, Siddhartha Institute of Technology and Sciences, Hyderabad, Telangana, India.

R. Saritha, Assistant Professor,Department of Civil Engineering, India.

T. Ashok, Assistant Professor,Department of Civil Engineering, Siddhartha Institute of Technology and Sciences, Hyderabad, Telangana, India. Siddhartha Institute of Technology and Sciences, Hyderabad, Telangana,

prerequisite

forreductioninthecostofconcrete, hasresultedintheincreasenee dtoidentifysubstitutematerialtosandasfine total particularly within the strong. Quarry dirt is coming approximately as factor-effect in the course of rock quarrying sporting occasions. The present work endeavored to lessen fee of cement thru making use of quarry dirt as incomplete substitution of sand in concrete and midway substitution of bond via fly particles and limesludge.

On this paper an examination has been made for the development of savvy robust making use of mechanical waste material like fly particles, lime slop and quarry sand (quarry dust). This moreover enables in taking care of switch problem of fly debris, lime ooze and quarry residue quite.

\section{LITERATURE REVIEW}

Sarika G.Javiya et al [1]studied Hypo slop use in mortar via supplanting bond via hypo ooze closer to compressive remarkable, water ingestion and sorptivity with severa time slips. Within the reference paper[2], Aman jatale et al, finished examination on impact of fly particles on mechanical houses of the solid like functionality, placing time, thickness, air content material cloth, compressive best by using supplanting the bond with $20 \%$,forty $\%$ and $60 \%$ of fly debris. M15,M20 and M25. The modulus of versatility of robust declines with increment of substitution of concrete by way of hypo slime is accounted for by Solanki and Pitroda[3]. Usage of hypo-ooze in asphalt development will improve transportation usefulness and environmental supportability and effects in created visitors safety and lessens lifestyles cycle fee by way of Pitroda et al [4].

\section{MATERIALS USED}

The fixings applied in the composite cement are normal Portland concrete, coarse overall, tremendous fashionable (sand), quarry sand (quarry dirt), fly particles and lime-slop. The lime slop is squander object from paper enterprise. The fly particles is the waste material from coal enterprise. The physical homes like explicit gravity and so forth are gotten from the studies center. The subtleties of various materials utilized inside the composite cement are givenbelow:

Common Portland concrete (OPC) of 503 evaluations taken in a solitary region, from extremely Tech bond company have become utilized over the span of the exam. The particular gravity of concrete is three.05. Close by waterway sand modified into applied, placing forward to the usual particulars of IS 383-1970[5]. It falls underneath the

Published By: 
type region - III. Specific gavity of the sand is 2.6. Domestically available coarse totals of $20 \mathrm{~mm}$ cut decrease returned had been utilized. Specific gravity of the route normal is two.Sixty 4. The consumable water is implemented on this exam..

Fly debris of sophistication-C grade become received from Bellary warmness electricity plant and a solitary parcel changed into applied in the course of the examinations. It become sans dry from irregularities and is of gray in shading. The specific gravity of fly particles is 2.46 . The lime slop is the waste fabric from the paper business organisation. The lime ooze implemented in this task artwork is amassed from Mysore Paper mills Bhadravathi, Shivamogga location, Karnataka. It's miles white in shading, searching like slaked lime. The best gravity of lime muck is two.38. The quarry sand (quarry dust) utilized here is brought from the quarries of North Bangalore and sieved via the IS four.75mm strainer. The particular gravity of the quarry sand (in any other case referred to as quarry dirt ) is .Forty one

\section{EXPERIMENTAL PROCEDURE}

Fabric houses of fixings like specific gravities of bond, best total and coarse fashionable, fly debris and copper slag were resolved in stable Lab. Dampness substance and water ingestions of best normal and coarse overall and copper slag have been moreover determined in the solid Lab. Utilizing these consequences the robust blend configuration has been finished for M30 grade concrete in line with may be: 102622009[6]. Arrangement of stable 3D shapes of cutting-edge measurements (a hundred fifty $\mathrm{mm} x$ one hundred fifty $\mathrm{mm}$ $x$ a hundred fifty $\mathrm{mm}$ ), strong chambers of fashionable dimension (150mm width and three hundred mm tallness) and robust crystals of standard measurements $(100 \mathrm{~mm} \mathrm{x}$ $100 \mathrm{~mm} \times 500 \mathrm{~mm}$ ) were thrown with particular aggregate extents as indicated in table four. 1 and were relieved for 28 days or 60 days. These restored stable three-D shapes have been tried for compressive quality in strain sorting out machine in keeping with appears to be: 516-1959[7]. Solid chambers were tried for pressure consistent with may be: 5816-1976[8]. Plain solid crystals were attempted for flexural exceptional consistent with appears to be: 516-19.

Table 4.1 Mix proportions of ingredients for composite concrete

\begin{tabular}{|c|c|c|c|c|c|c|c|}
\hline $\begin{array}{c}\text { Grad } \\
\text { e of } \\
\text { Conc } \\
\text { rete }\end{array}$ & $\begin{array}{c}\text { Notatio } \\
\text { n Mix } \\
\text { types }\end{array}$ & \multicolumn{6}{|c|}{ Ingredients in \% by weight } \\
\cline { 3 - 8 } & & $\begin{array}{c}\text { Ceme } \\
\text { nt }\end{array}$ & $\begin{array}{c}\text { Fly } \\
\text { Ash }\end{array}$ & $\begin{array}{c}\text { Hy } \\
\text { po } \\
\text { Slu } \\
\text { dg } \\
\text { e }\end{array}$ & Sand & $\begin{array}{c}\text { Quarr } \\
\text { y } \\
\text { Sand }\end{array}$ & $\begin{array}{c}\text { Coarse } \\
\text { Aggreg } \\
\text { ate }\end{array}$ \\
\hline \multirow{4}{*}{ M30 } & C0 & 100 & 0 & 0 & 100 & 0 & 100 \\
\cline { 2 - 9 } & $\mathrm{C} 1$ & 80 & 10 & 10 & 80 & 20 & 100 \\
\cline { 2 - 9 } & $\mathrm{C} 2$ & 70 & 10 & 20 & 80 & 20 & 100 \\
\cline { 2 - 9 } & $\mathrm{C} 3$ & 60 & 10 & 30 & 80 & 20 & 100 \\
\cline { 2 - 8 } & $\mathrm{C} 4$ & 50 & 10 & 40 & 80 & 20 & 100 \\
\cline { 2 - 8 } & $\mathrm{C} 5$ & 70 & 15 & 15 & 80 & 20 & 100 \\
\hline
\end{tabular}

\section{TEST RESULTS AND DISCUSSIONS}

The compressive strength, flexural power and tensile power split simple concrete (without accommodations or industrial waste substances) has been as compared to the compressive electricity, flexural energy and electricity break up tensile composite concrete made with commercial waste substances fly ash, lime dust and sand mining after 28 and 60 day therapy.

\section{1 composite concrete dice compressive power}

Series of concrete cubes were casted as per The extent of the blend inside the table following 28 days and 60 days to treatment the shakers has been tried the use of motor pressure test and the outcomes are shown in the individual Figures 5.1 and 5.2. These outcomes recommend that 10 percent substitute of bond with fly debris and 10 level of concrete with hypo muck following 60 days of restoring has finished in almost the indistinguishable vitality of the solid is overseen or certain. So also increment inside the substance material of the lime ooze prompted a reduction solid shape compressive power. What's more, as it isn't supported to apply lime mud content material of in excess of ten level of the substance of straightforward solid concrete in which bond has been in part supplanted by method for fly debris 10persen.

\subsection{Split elasticity of the composite concretecylinders}

Arrangement of composite solid chambers of a hundred and fifty $\mathrm{mm}$ width and $300 \mathrm{~mm}$ in top was manufactured the utilization of a blend extents are given in Table four. 1 and inspected following 28 days and 60 days to recuperate divisions know their elastic power. These impacts are plotted in Fig. Five.Three and Figure five.Four. These outcomes show that 10 rate substitute of bond with fly debris and 10 level of bond with hypo slime following 28 days and 60 days of restoring has brought about 18.Four rate and five percent more elasticity than the cut up of controlled or plain solid chambers each individually. Likewise blast inside the substance of the lime ooze finished in a reduction tensilestrength split.

\subsection{Flexural power of the composite concreteprisms}

Composite solid crystal assortment of standard components of $100 \mathrm{~mm}$ broad and $100 \mathrm{~mm}$ profound and $500 \mathrm{~mm}$ had been thrown the utilization of a mix extents are given in Table four. 1 and analyzed following 28 days and 60 days to recuperate knowing their flexural quality. These results are plotted in Fig. 5.5

And Figure five.6. These effects indicate that 10 percent replacement of cement with fly ash and 10 percent of cement with hypo sludge after 28 days and 60 days of curing has led to 6.67 percent and six.Eighty according to cent greater flexural strength than that of controlled or plain concrete prisms respectively. In addition increase inside the content of the lime sludge resulted in a decrease inside the bending energy. 


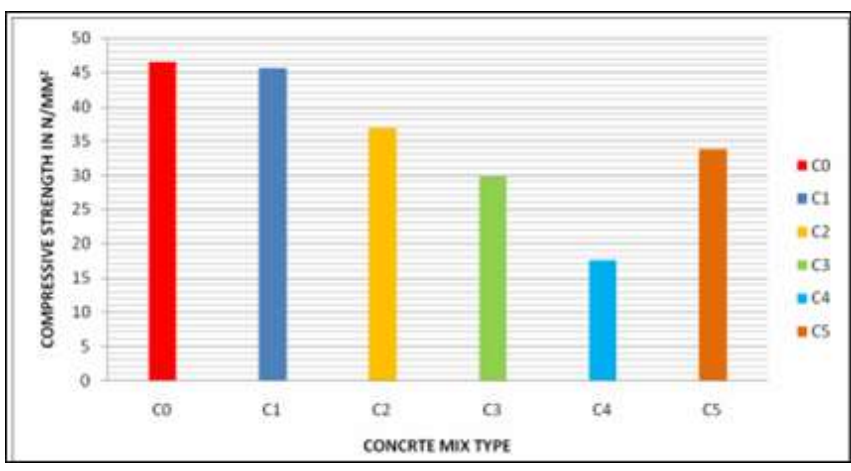

Fig 5.1: Compressive strengths of composite concrete cubes at 28 days curing

Fig 5.2: Compressive Strength of composite concrete cubes at 60 days curing

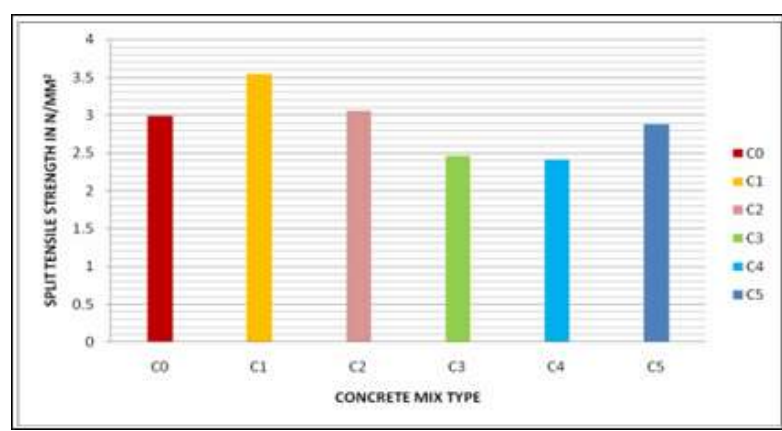

Fig. 5.3 Split tensile strength of composite concrete cylinders at 28 days curing

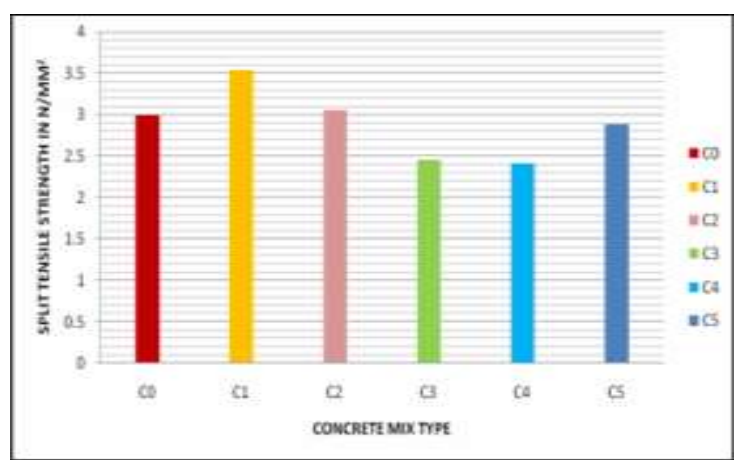

Fig. 5.4 Split tensile strength of composite concrete cylinders at 60 days curing

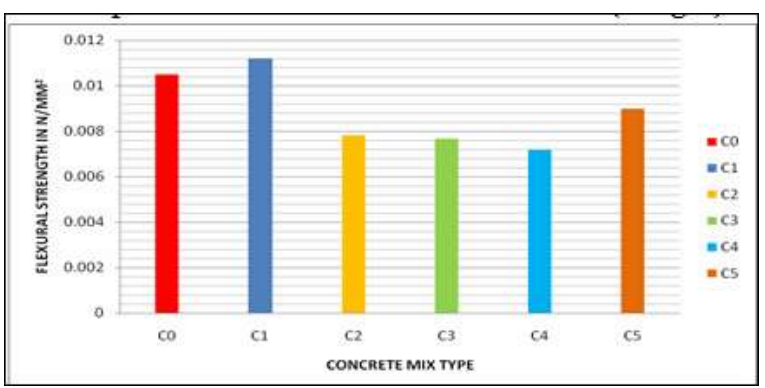

Fig. 5.5 Flexural strength of composite concrete prisms at 28 days curing

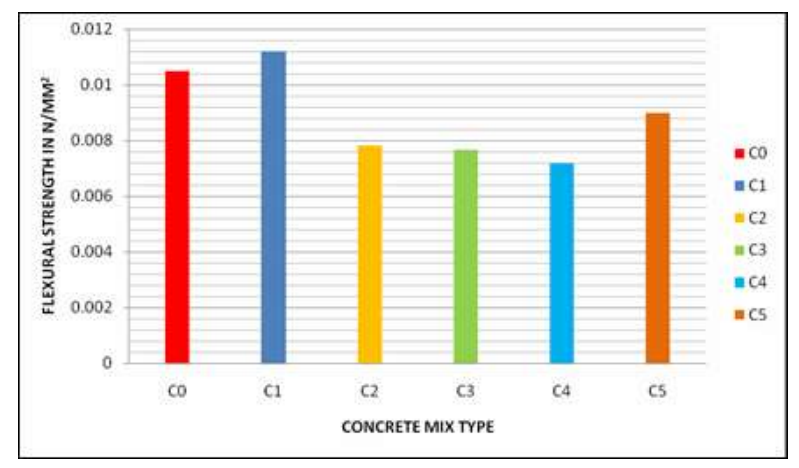

Fig 5.6 Flexural strength of composite concrete prisms at 60 days curing

\section{CONCLUSIONS}

In this exploration, a look at has been accomplished for the improvement of significant worth amazing solid utilizing modern waste substances alongside fly debris, lime residue and sand mines. From this examination the accompanying ends were drawn:

1. The composite cement with a 10 percent option of bond (weight) with fly debris and 10 percent substitute of bond with lime dust (weight) produces compressive power of solid blocks have been marginally lower inside the 28day cure and about the equivalent compressive vitality at 60 days fix, in standard, when contrasted with the compressive quality (plain) customary cement. Further substitution of bond by lime ooze (extra than 10 rate) will decrease the compressive intensity of cement under vitality (plain) traditional cement.

2. Since the composite mix with 10 percent option of bond (weight) with fly debris and 10 rate substitute of concrete with lime dust (weight) created, in far reaching, are nearly the indistinguishable compressive power, split ductile and flexural quality higher in examination with straightforward cement. There is a 20 percent (10 rate fly debris and 10 rate with the guide of lime slop) cost money related investment funds of bond and sand to twenty rate expense budgetary reserve funds as it is supplanted by utilizing sand mining, this could be done with those composite blend.Further cure transfer issues total of fly debris, lime muck and sand pit to a definite amount.

3. Over the composite blend this is 10 rate substitution of bond (weight) with fly debris and 10 rate option of bond with lime dust (weight) results in extra tractable power riven with the guide of 18.Four as indicated by penny and 5 in step with penny in examination with the separation pliable power regular (ordinary) concrete following 28 days and 60 days of restoring separately. Further option of bond by utilizing lime ooze (more than 10 rate) may decrease the elastic power of solid divisions under power (unquestionable) customary cement.

4. Over the composite blend this is 10 percent substitution of bond (weight) with fly debris and 10 percent option of bond with lime mud (weight) additionally delivers additional vitality supple with 6 .Sixty seven percent and 
6.Eight rate contrasted and the flexural concrete convectional following 28 days and 60 days of relieving separately.

\section{SCOPE OF WORK INSIDE THE FATE}

1. Penetrability appraisals on composite solid blend must be done to assess the Secure concrete fragment transformed into basically advantageous in making experience of the amount of steel disintegration strong hard shape.

2. Durability generally stable participation should be appeared through test using at or extra than 60 days for compressive quality, split elastic and flexural quality of cement.

\section{REFERENCES}

1. Sarika G. Javiya, Zalak P.Shah and Rushabh shah „, A mortar Development of low value by means of using the waste paper slop Hypo endeavor, International magazine for logical research and improvement, 2, 2014, 23210613.

2. Safe Jatale, Kartkey Tiwari, Sahil Khandelwal, Effects on the Compressive Strength while Semen Most Succeeded through Fly-Ash, IOSR Engineering and Civil Engineering Journal, 2013, 5, 34-forty three.

3. Solanki and Pitroda, Study modulus of flexibility of cement with fractional option of concrete by hypo sewage slop from the paper venture, the International diary of floor building time, 2013, 2, 2277-8160

4. Pitroda, Zala and Umrigar, Hypo Utilization Sludge by utilizing Eco-Efficient Development in Rural Roads Rigid Pavement, International Journal of Engineering and Technology Trends, 2013, four 0.44-49

5. IS: 383-1976, Specifications of coarse and fine totals from characteristic assets for solid, Bureau of Indian Standards, New Delhi

6. IS: 10262-2009, Recommended Concrete Mix Design Guidelines, the Bureau of Indian Standards. New Delhi

7. IS: 516-1959, strategy for looking at the intensity of cement, the Bureau of Indian Standards, New Delhi

8. IS: 5816-1999, Separates ductile intensity of solid testing strategies, the Bureau of Indian Standards, New Delhi 